\title{
Jeune Syndrome
}

National Cancer Institute

\section{Source}

National Cancer Institute. Jeune Syndrome. NCI Thesaurus. Code C84794.

A rare autosomal recessive inherited syndrome characterized by a narrow thorax, micromelia, and respiratory disturbances which may lead to asphyxiation. It may be associated with bilateral microcystic renal disease which may lead to renal failure. 